\title{
Substâncias húmicas e suas relações com o grau de subsidência em Organossolos de diferentes ambientes de formação no Brasil ${ }^{1}$
}

\author{
Humic substances and their relationship to the degree of subsidence of histosols in \\ different formation environments in Brazil
}

\author{
Adierson Gilvani Ebeling²*, Lúcia Helena Cunha dos Anjos ${ }^{3}$, Marcos Gervasio Pereira ${ }^{3}$, Gustavo Souza \\ Valladares ${ }^{4}$ e Daniel Vidal Pérez ${ }^{5}$
}

\begin{abstract}
RESUMO - A matéria orgânica do solo é parte de um sistema dinâmico influenciado por vários fatores, incluindo clima, conteúdo e natureza das argilas, uso da terra, sistemas de manejo e drenagem, os quais afetam as taxas de adição e os processos de transformações e evolução dos compostos orgânicos. O objetivo deste trabalho foi quantificar e avaliar a distribuição das frações húmicas em Organossolos de diferentes ambientes e regiões do Brasil, relacionando-os com os processos de subsidência. O teor de carbono (C) nas substâncias húmicas indicou predomínio do C da fração ácido húmico (C-FAH de 22,1 $\mathrm{g} \mathrm{kg}^{-1}$ a 153,7 $\mathrm{g} \mathrm{kg}^{-1}$ ) nos solos de regiões altimontanas e ambientes de planalto. Possivelmente, o clima mais frio, aliado a uma melhor fertilidade, favoreceu a formação desta fração em detrimento das frações ácido fúlvico e humina. Por outro lado, o maior teor de ácidos húmicos torna os Organossolos nesses ambientes mais susceptíveis aos processos de subsidência, principalmente quando manejados para agricultura. Já nos ambientes de várzeas e de planícies litorâneas, houve maior formação do C da fração humina (C-HUM de 79,2 a 267,2 g kg-1), que é a fração das substâncias húmicas mais resistente à decomposição. O somatório das frações húmicas representou 89\% do carbono total, estando essas duas variáveis altamente correlacionadas. A relação Extrato alcalino humina (EA/HUM) agrupou classes de Organossolos pelo ambiente de formação, sendo sugerida como atributo diagnóstico nos níveis inferiores do Sistema Brasileiro de Classificação de Solos (SiBCS), possibilitando diferenciar os Organossolos quanto ao potencial de subsidência.
\end{abstract}

Palavras-chave: Substâncias húmicas. Húmus. Várzeas.

\begin{abstract}
The organic matter of soil is part of a dynamic system influenced by several factors, including climate, the content and nature of clays, land use, management and drainage systems, all of which affect the addition rates, and the processes of transformation and evolution of organic compounds. The objective of this study was to quantify and assess the distribution of humic fractions in histosols in different environments and regions of Brazil, relating them to the processes of subsidence. The carbon (C) content in humic substances indicated a predominance of $\mathrm{C}$ from the humic-acid fraction (HAF-C of $22.1 \mathrm{~g} \mathrm{~kg}^{-1}$ to $153.7 \mathrm{~g} \mathrm{~kg}^{-1}$ ) in soils from high altitude mountainous regions and upland areas. Possibly the colder climate, coupled with improved fertility, favored the formation of this fraction at the expense of the fulvic acid and humin fractions. On the other hand, the higher humic-acid content makes organosols in these environments more susceptible to the processes of subsidence, especially when under agricultural management. Whereas in flood and coastal-plain environments, there was a greater formation of $\mathrm{C}$ from the humin fraction (HUM-C from 79.2 to $267.2 \mathrm{~g} \mathrm{~kg}^{-1}$ ), being the fraction of humic substances most resistant to decomposition. The sum of the humic fractions represented $89 \%$ of the total carbon, these two variables being highly correlated. The relationship between alkaline extract and humin (AE/HUM) groups classes of histosols by their formation environment, and is suggested as a diagnostic attribute at the lower levels of the Brazilian System for Soil Classification (SiBCS), allowing differentiation of the histosols as to their potential for subsidence.
\end{abstract}

Key words: Humic substances. Humus. Floodplains.

\footnotetext{
Recebido para publicação em 06/09/2011; aprovado em 30/08/2012

Parte da Dissertação de Mestrado do primeiro autor apresentada ao Curso de Pós-graduação em Agronomia, Ciência do Solo/CPGA-CS da Universidade Federal Rural do Rio de Janeiro/UFRRJ Seropédica-RJ. Projeto financiado pelo CNPq

${ }^{2}$ Emater/Pesagro/Estação Experimental da Pesagro, Estrada Velha do Glicério, km 3, Macaé-RJ, Brasil, 27.901-630, adiersonge@gmail.com

${ }^{3}$ Departamento de Solos, Instituto de Agronomia/UFRRJ, BR 465, km 7, Seropédica-RJ, Brasil, 23.890-000 lanjos@ufrrj.br, gervasio@ufrrj.br ${ }^{4}$ Departamento de Geografia e Historia, Centro de Ciências Humanas e Letras, Universidade Federal do Piauí/UFPI, Teresina-PI, Brasil, 64.049-550, valladares@ufpi.edu.br

${ }^{5}$ Embrapa Solos, Rua Jardim Botânico 1024, Rio de Janeiro-RJ, Brasil, 22.460-000, daniel@ cnps.embrapa.br
} 


\section{INTRODUÇÃO}

$\mathrm{O}$ estoque de carbono (C) de um solo sob vegetação natural representa o balanço dinâmico entre as adições de material vegetal morto e as suas perdas pela decomposição, mineralização, lixiviação ou erosão (DAI; PING; MICHAELSON, 2002, DAVIDSON; JANSSENS, 2006). As taxas de adição e a natureza do $C$ dependem do clima, do tipo de vegetação e da fertilidade do solo (BAYER et al., 2006; EBELING et al., 2011b; LAL, 2004).

Segundo Stevenson (1994), as SHs são constituídas por uma série de compostos de coloração castanha ou preta, de elevado peso molecular, formados por reações de sínteses secundárias bióticas e abióticas que são separadas com base em suas características de solubilidade e classificadas em: (i) humina: fração insolúvel em álcali e em ácido; (ii) ácidos húmicos: fração de coloração escura extraída geralmente em meio alcalino $\left(\mathrm{NaOH}\right.$ e $\left.\mathrm{Na}_{4} \mathrm{P}_{2} \mathrm{O}_{7}\right)$ e insolúvel em meio ácido diluído; e (iii) ácidos fúlvicos: material castanho claro que permanece em solução após a remoção dos ácidos húmicos por acidificação. Uma porção dos ácidos húmicos, por sua vez, pode ser solúvel em álcool constituindo os chamados ácidos hematomelânicos. As SHs são diferentes dos biopolímeros do solo, principalmente pela sua estrutura mais complexa e longa persistência no solo (DICK et al., 2005; HAYES; CLAPP, 2001). Quanto à caracterização, Novotny et al. (2006) as identifica como substâncias amorfas, de cor preta, parcialmente aromáticas, principalmente hidrofílicas e quimicamente complexas.

Dentre as classes de solos descritas no Sistema Brasileiro de Classificação de Solos (SiBCS) (EMPRESA BRASILEIRADE PESQUISAAGROPECUÁRIA, 2006), encontram-se os Organossolos que apresentam como característica principal teores de C orgânico superiores a $80 \mathrm{~g} \mathrm{~kg}^{-1}$ de solo.

Adecomposição dos materiais orgânicos nas turfas e nos Organossolos em ambientes de várzea é acelerada com a drenagem, em um processo denominado de subsidência. Sua intensidade depende da natureza do material orgânico, da sua capacidade de adsorção de água, da proporção de material mineral no solo e da profundidade de drenagem. (ANDRIESSE, 1984; CONCEIÇÃO, 1989). Todos os solos orgânicos originados de sedimentos turfosos, podem ser afetados pelo processo de subsidência. A subsidência em solos orgânicos em ambiente de várzea e em turfeiras é um processo dinâmico e ocorre por dois fenômenos principais. $\mathrm{O}$ primeiro deve-se à remoção, pela força flutuante de empuxo da drenagem, de material mais leve, flutuante, que existia quando o solo estava saturado (EWING; VEPRASKAS, 2006) e o segundo se dá com a drenagem do material com elevado teor de matéria orgânica, antes preservada pelas condições de saturação por água. Ao expor o material orgânico a ambiente rico em oxigênio se inicia outra fase do processo de subsidência, pela oxidação heterotrófica (AMBAK; MELLING, 2000; DRADJAD et al., 2003) por microrganismos aeróbios (TATE, 1980) e por queima do material vegetal.

Logo caracterizar as SHs desses solos, é fundamental, para obter uma maior compreensão dos processos de perda da matéria orgânica, comumente relacionados com a subsidência, ou ações antrópicas. Entretanto, poucos são os trabalhos com fracionamento químico das SHs em solos orgânicos em regiões de clima tropical (VALLADARES et al., 2007). Ainda, a caracterização química das SHs é relevante em estudos sobre origem e evolução da matéria orgânica dos Organossolos, particularmente daqueles que são afetados pela subsidência (VALLADARES et al., 2008). Podendo as SHs servir para classificar os Organossolos nos $5^{\circ}$ e $6^{\circ}$ níveis do SiBCS (FONTANA et al., 2011; VALLADARES et al., 2003).

O objetivo deste trabalho foi quantificar e avaliar a distribuição das substâncias húmicas em Organossolos formados em diferentes ambientes do Brasil. E ainda, identificar propriedades químicas que possam estar relacionadas ao potencial de subsidência dos Organossolos em função do ambiente de origem.

\section{MATERIAL E MÉTODOS}

Foram coletados 11 (onze) perfis de Organossolos de diferentes regiões do Brasil, totalizando 32 (trinta e dois) horizontes (Tabela 1). Após a coleta dos materiais segundo (SANTOS et al., 2005), os solos foram caracterizados quanto às suas propriedades físicas e químicas segundo Empresa Brasileira de Pesquisa Agropecuária (1997) e classificados conforme o SiBCS (EMPRESA BRASILEIRA DE PESQUISA AGROPECUÁRIA, 2006).

O fracionamento das SHs foi feito em triplicata (3 extrações para cada amostra), sendo aplicada a técnica da solubilidade diferencial (DABIN, 1976; KONONOVA, 1982), utilizando-se os conceitos de frações húmicas estabelecidos pela Sociedade Internacional de Substâncias Húmicas, adaptado por Benites, Madari e Machado (2003). O teor deC das frações húmicas foi quantificado segundo Yeomans e Bremmer (1988). Após as determinações analíticas foram calculados os teores de carbono das três frações húmicas (ácidos húmicos, ácidos fúlvicos e humina) e as relações entre os teores de $\mathrm{C}$ das diferentes frações, sendo elas C-FAH/C-FAF, extrato alcalino $(\mathrm{EA}=\mathrm{C}-\mathrm{FAF}+\mathrm{C}-\mathrm{FAH})$ e EA/C-HUM.

O C total foi determinado pelo método de combustão a seco usando um analisador elementar Modelo Perkin Elmer 2400 CHNS, no laboratório da 
Tabela 1 - Localização, classificação do solo, tipo de vegetação, classe de drenagem e altitude dos sítios de solos

\begin{tabular}{|c|c|c|c|c|c|c|}
\hline Estado $1 /$ Perfil & Município/Ambiente ${ }^{2}$ & Classificação do solo ${ }^{3}$ & Vegetação & Drenagem & Alt. (m) & Temp. $\left({ }^{\circ} \mathrm{C}\right)$ \\
\hline AL-2 & Coruripe (a) & $\begin{array}{c}\text { Organossolo Tiomórfico } \\
\text { Hêmico típico }\end{array}$ & $\begin{array}{l}\text { Floresta tropical } \\
\text { subperenifólia de } \\
\text { várzea }\end{array}$ & Mal drenado & 5 & 24,4 \\
\hline BA-2 & Ituberá (a) & $\begin{array}{c}\text { Organossolo Tiomórfico } \\
\text { Hêmico térrico }\end{array}$ & $\begin{array}{l}\text { Floresta hidrófila } \\
\text { de restinga }\end{array}$ & $\begin{array}{l}\text { Mal a } \\
\text { imperfeitamente } \\
\text { drenado }\end{array}$ & 25 & 25,4 \\
\hline RJ-3 & $\begin{array}{l}\text { José da Boa } \\
\text { Morte (a) }\end{array}$ & $\begin{array}{c}\text { Organossolo Háplico } \\
\text { Hêmico térrico }\end{array}$ & $\begin{array}{l}\text { Floresta não } \\
\text { hidrófila de } \\
\text { restinga c/ lavoura } \\
\text { de subsistência }\end{array}$ & $\begin{array}{l}\text { Muito } \\
\text { drenado }\end{array}$ & 40 & 23,2 \\
\hline RS-4 & Viamão (a) & $\begin{array}{c}\text { Organossolo Tiomórfico } \\
\text { Sáprico típico }\end{array}$ & $\begin{array}{l}\text { Campos } \\
\text { subtropicais } \\
\text { hidrófilos de várzea }\end{array}$ & Mal drenado & 20 & 18,1 \\
\hline SC-2 & $\begin{array}{c}\text { Governador Celso } \\
\text { Portela (a) }\end{array}$ & $\begin{array}{c}\text { Organossolo Tiomórfico } \\
\text { Hêmico típico }\end{array}$ & $\begin{array}{l}\text { Floresta subtropical } \\
\text { hidrófila de várzea }\end{array}$ & $\begin{array}{l}\text { Muito } \\
\text { drenado }\end{array}$ & 10 & 18,2 \\
\hline DF-1 & Guará II (b) & $\begin{array}{c}\text { Organossolo Háplico } \\
\text { Sáprico típico }\end{array}$ & $\begin{array}{l}\text { Floresta tropical } \\
\text { subperenifólia }\end{array}$ & Mal drenado & 800 & 19,2 \\
\hline MG-2 & Coronel Pacheco (b) & $\begin{array}{c}\text { Organossolo Háplico } \\
\text { Hêmico terrico }\end{array}$ & $\begin{array}{l}\text { Floresta subtropical } \\
\text { higrófila de várzea }\end{array}$ & $\begin{array}{l}\text { Muito } \\
\text { drenado }\end{array}$ & 432 & 21,1 \\
\hline MS-2 & Porto Morumbi (b) & $\begin{array}{l}\text { Organossolo Tiomórfico } \\
\text { Sáprico terrico }\end{array}$ & $\begin{array}{l}\text { Floresta subtropical } \\
\text { higrófila de várzea }\end{array}$ & $\begin{array}{l}\text { Muito } \\
\text { drenado }\end{array}$ & 280 & 19,2 \\
\hline PR-2 & Tijucas do Sul (b) & $\begin{array}{c}\text { Organossolo Háplico } \\
\text { Sáprico típico }\end{array}$ & $\begin{array}{l}\text { Floresta subtropical } \\
\text { mista de araucárias }\end{array}$ & $\begin{array}{l}\text { Muito mal } \\
\text { drenado }\end{array}$ & 850 & 21,3 \\
\hline RJ-4 & Nova Friburgo (b) & $\begin{array}{l}\text { Organossolo Háplico } \\
\text { Sáprico térrico }\end{array}$ & $\begin{array}{l}\text { Floresta subtropical } \\
\text { higrófila de várzea }\end{array}$ & Mal drenado & 800 & 16,0 \\
\hline SP-1 & Taubaté (b) & $\begin{array}{c}\text { Organossolo Háplico } \\
\text { Sáprico térrico }\end{array}$ & $\begin{array}{l}\text { Floresta subtropical } \\
\text { higrófila de várzea }\end{array}$ & Mal drenado & 500 & 23,0 \\
\hline
\end{tabular}

${ }^{1}$ Unidade Federativa do Brasil: AL, Alagoas; BA, Bahia; DF, Distrito Federal, Brasília; MG, Minas Gerais; MS, Mato Grosso do Sul; PR, Paraná; RJ, Rio de Janeiro; RS, Rio Grande do Sul; SC, Santa Catarina; SP, São Paulo; 2 Ambientes: a - Ambiente de várzea e planície litorânea; $b$ - Ambiente de regiões altimontanas e de planalto; $3 \mathrm{SiBCS}$, Embrapa (2006)

Embrapa Solos - Rio de Janeiro (RJ). Para atender ao método de referência preconizado noSiBCS(EMPRESA BRASILEIRA DE PESQUISA AGROPECUÁRIA, 2006), foi determinado o teor de matéria orgânica (MO) com auxílio de forno mufla. Esse método de combustão seca da MO baseia-se na diferença de massa da amostra de solo antes e após carbonização. Foram utilizados cerca de $10 \mathrm{~g}$ de solo, previamente seco em estufa $\left(105^{\circ} \mathrm{C}\right)$ por $24 \mathrm{~h}$, macerados, peneirados em peneira de 100 mesh e pesados, sendo colocado em um forno mufla e deixado por $6 \mathrm{~h}$ a $600{ }^{\circ} \mathrm{C}$. O conteúdo de matéria orgânica foi determinado por diferença de massa em relação à amostra original seca em estufa. Os resultados foram analisados através de métodos de estatística descritiva e análise de correlação linear simples de Pearson, utilizando-se o software Microsoft Excel (Versão 2003).

\section{RESULTADOS E DISCUSSÃO}

\section{Distribuição das frações húmicas da matéria orgânica}

A distribuição das frações húmicas da MO no conjunto dos Organossolos indica o predomínio do $\mathrm{C}$ da fração humina (C-HUM), com valor médio de $118,8 \mathrm{~g} \mathrm{~kg}^{-1}$, porém com elevado coeficiente de variação (CV) $(77 \%)$, sendo os valores mínimo e máximo de 3,5 e $267,2 \mathrm{~g} \mathrm{~kg}^{-1}$, respectivamente (Tabela 2). Quando os perfis foram agrupados em função do ambiente de formação (Tabela 3), nota-se que, para os Organossolos em ambiente de várzeas e planícies litorâneas (perfis AL-2, BA-2, SC-2, RS-4, RJ-3) a fração humina apresentou teor de $\mathrm{C}$ médio mais elevado (196 $\mathrm{g} \mathrm{kg}^{-1}$ ), dentre todas as frações, com menor CV (32\%), quando comparada ao total de perfis analisados (Tabela 2). Essa diferenciação em função do ambiente de formação reflete 
Tabela 2 - Teores de C nas frações ácido fúlvico, ácido húmico, humina, somatório das frações, em relação ao solo e ao C total, e relações entre as frações e o extrato alcalino

\begin{tabular}{|c|c|c|c|c|c|c|c|c|c|}
\hline \multirow{2}{*}{ Perfil } & \multirow{2}{*}{ Horiz. } & \multirow{2}{*}{ Prof. } & FAF & FAH & HUM & SOMA & Ctotal & \multirow{2}{*}{ FAH:FAF } & \multirow{2}{*}{ EA:HUM } \\
\hline & & & \multicolumn{5}{|c|}{$\mathrm{g} \mathrm{C} \mathrm{kg}^{-1}$ solo } & & \\
\hline \multirow[t]{4}{*}{ AL-2 } & Hdojp & $0-23$ & 23,9 & 127,0 & 152,3 & 303,2 & 305,8 & 5,5 & 1,0 \\
\hline & Hdoj1 & $23-32$ & 24,3 & 193,8 & 225,6 & 443,7 & 508,1 & 8,0 & 1,0 \\
\hline & Hdoj2 & $32-65$ & 21,2 & 139,7 & 232,7 & 393,6 & 454,7 & 6,6 & 0,7 \\
\hline & Hoj & $65-150$ & 9,2 & 22,0 & 79,2 & 110,4 & 120,7 & 2,4 & 0,4 \\
\hline \multirow[t]{3}{*}{ BA-2 } & Hdoj1 & $0-15$ & 23,2 & 185,7 & 252,8 & 461,7 & 525,3 & 8,0 & 0,8 \\
\hline & Hdoj2 & $15-32$ & 23,8 & 188,8 & 267,2 & 479,8 & 528,5 & 7,9 & 0,8 \\
\hline & Hdoj3 & $32-81$ & 16,7 & 178,5 & 172,8 & 368,0 & 371,9 & 11,4 & 1,2 \\
\hline \multirow[t]{4}{*}{ RJ-3 } & Hdp & $0-25$ & 35,5 & 115,3 & 131,8 & 282,6 & 339,8 & 3,2 & 1,2 \\
\hline & Hdo1 & $25-45$ & 42,5 & 121,2 & 139,2 & 302,9 & 314,9 & 2,8 & 1,2 \\
\hline & Hdo2 & $45-63$ & 51,0 & 104,8 & 99,7 & 255,5 & 332,3 & 2,0 & 1,6 \\
\hline & Hdo & $63-90$ & 24,0 & 95,2 & 184,4 & 303,6 & 312,5 & 4,0 & 0,6 \\
\hline \multirow[t]{3}{*}{$\mathrm{RS}-4$} & Hdpj & $0-16$ & 19,4 & 160,7 & 199,4 & 379,5 & 425,7 & 8,3 & 0,9 \\
\hline & Hdj & $16-80$ & 16,5 & 153,7 & 240,1 & 410,3 & 482,2 & 9,3 & 0,7 \\
\hline & Hdoj & $80-120^{+}$ & 12,0 & 138,4 & 256,3 & 406,7 & 490,0 & 11,5 & 0,5 \\
\hline \multirow[t]{2}{*}{$\mathrm{SC}-2$} & Hdoj1 & 0-20 & 30,9 & 143,1 & 235,6 & 409,6 & 460,0 & 4,6 & 0,7 \\
\hline & Hdoj2 & $20-100$ & 24,5 & 188,4 & 260,3 & 473,2 & 528,1 & 7,7 & 0,8 \\
\hline \multirow[t]{3}{*}{ DF-1 } & Hdp & $0-26$ & 16,3 & 67,3 & 43,5 & 127,1 & 132,4 & 3,2 & 1,9 \\
\hline & Hd1 & $26-48$ & 17,8 & 119,0 & 35,1 & 171,9 & 196,6 & 4,1 & 3,9 \\
\hline & $\mathrm{Hd} 2$ & $48-80+$ & 19,1 & 47,0 & 88,0 & 154,1 & 179,8 & 6,7 & 0,7 \\
\hline \multirow[t]{2}{*}{ MG-2 } & Hd & 0-20 & 14,0 & 45,1 & 61,1 & 120,2 & 124,8 & 3,2 & 1,0 \\
\hline & 2Hdo & $20-60$ & 11,9 & 68,5 & 105,7 & 186,1 & 206,4 & 5,7 & 0,8 \\
\hline \multirow[t]{2}{*}{ MS-2 } & Hd1 & $0-40$ & 20,2 & 52,3 & 41,4 & 113,9 & 121,1 & 2,6 & 1,7 \\
\hline & $\mathrm{Hd} 2$ & $150-180^{+}$ & 7,3 & 99,4 & 79,6 & 186,3 & 189,3 & 13,6 & 1,3 \\
\hline \multirow[t]{3}{*}{ PR-2 } & Hdp1 & 0-20 & 13,1 & 89,5 & 36,5 & 139,1 & 144,1 & 6,8 & 2,8 \\
\hline & Hdp2 & $20-55$ & 9,9 & 143,4 & 30,7 & 184,0 & 192,8 & 14,4 & 5,0 \\
\hline & Hdp3 & $55-120^{+}$ & 21,0 & 153,7 & 39,6 & 214,3 & 270,0 & 7,3 & 4,4 \\
\hline \multirow[t]{4}{*}{ RJ-4 } & Hdp1 & 0-9 & 15,6 & 30,5 & 20,9 & 67,0 & 91,7 & 1,9 & 2,2 \\
\hline & Hdp2 & $9-43$ & 17,2 & 34,2 & 8,9 & 60,3 & 99,5 & 2,0 & 5,8 \\
\hline & Hdp3 & 43-67 & 12,7 & 22,4 & 3,5 & 38,6 & 69,8 & 1,8 & 9,9 \\
\hline & Hd & $97-115^{+}$ & 11,0 & 22,1 & 6,0 & 39,1 & 44,8 & 2,0 & 5,6 \\
\hline \multirow[t]{2}{*}{ SP-1 } & Hdp1 & 0-12 & 23,7 & 112,8 & 53,7 & 190,2 & 207,4 & 4,8 & 2,5 \\
\hline & Hdp2 & $12-45$ & 13,2 & 95,1 & 17,7 & 126,0 & 144,4 & 7,2 & 6,1 \\
\hline $\operatorname{Max}$ & & & 51,0 & 193,8 & 267,2 & 479,8 & 528,5 & 14,4 & 9,9 \\
\hline Min & & & 7,3 & 22,0 & 3,5 & 38,6 & 44,8 & 1,8 & 0,4 \\
\hline Média & & & 20,1 & 108,1 & 118,8 & 247,0 & 278,6 & 6,0 & 2,2 \\
\hline DP & & & 9,5 & 54,4 & 91,0 & 140,3 & 157,3 & 3,5 & 2,2 \\
\hline $\mathrm{CV} \%$ & & & 47 & 50 & 77 & 57 & 56 & 58 & 101 \\
\hline
\end{tabular}

Horiz = Horizontes; Prof. = Profundidade; FAF = fração ácido fúlvico; FAH = fração ácido húmico; HUM = fração humina; SOMA = FAF + FAH + HUM; Ctotal = combustão a seco em analisador elementar PerKin Elmer 2400 CHNS; FAH:FAF = Relação entre a fração ácido húmico e a fração ácido fúlvico; EA:HUM = Relação entre o extrato alcalino $(\mathrm{FAF}+\mathrm{FAH})$ e a HUM.; Max. = Máximo; Min. = Mínimo; DP = Desvio padrão; CV\% = coeficiente de variação 
a influência da temperatura média anual na decomposição da matéria orgânica (DAI; PING; MICHAELSON, 2002), mesmo nos ambientes hidromórficos (HAYES; CLAPP, 2001; WEST; POST, 2002), favorecendo a formação da fração humina em relação às outras frações húmicas (BAYER et al., 2006; DAVIDSON; JANSSENS, 2006; DICK et al., 2005; EBELING et al., 2011a; 2011b).

Segundo alguns autores (KONONOVA, 1982; ORLOV, 1985; TAN, 2003), o predomínio da humina em ambientes hidromórficos pode ser atribuído ao processo de humificação direta dos tecidos lignificados modificados por demetilação, uma vez que os mecanismos de insolubilização e de neossíntese microbiana são bastante reduzidos. A presença de humina herdada, formada num período anterior e preservada em ambientes desfavoráveis à atividade microbiana plena, como o das turfeiras, pode também explicar o predomínio de C na fração humina (MILORI et al., 2002; TAN, 2003). Por outro lado, a baixa fertilidade natural dos Organossolos em ambientes de várzeas e planícies litorâneas, inundados periodicamente, diminui a intensidade dos processos de humificação, maiores detalhes podem ser observados em (EBELING et al., 2008, 2011a). Portanto, a relação C-FAH/C-FAF diminui, apesar de que ainda são mantidos valores maiores que um 1 (um). Como referência, para solos minerais, essa relação mostra geralmente valores menores que 1 (um) (ORLOV, 1985).

Na Tabela 3 são apresentadas as médias e a amplitude de variação dos teores de $\mathrm{MO}$ e dos teores de $\mathrm{C}$ nas frações húmicas e suas relações. Quando separa-se os horizontes pelo ambiente de formação percebe-se que a fração humina dos Organossolos de várzeas e das planícies litorâneas apresentou teor médio de $\mathrm{C}$ de $196 \mathrm{~g} \mathrm{~kg}^{-1}$ valor quase cinco vezes superior àquele de Organossolos de regiões altimontanas e de planalto $\left(42 \mathrm{~g} \mathrm{C} \mathrm{kg}^{-1}\right)$, sendo os CVs de 31 e $71 \%$, respectivamente. A amplitude foi muito alta nos ambientes de várzeas e de planícies litorâneas (Tabela 2), apresentando valores mínimo e máximo de 79,2 e $267,2 \mathrm{~g} \mathrm{~kg}^{-1}$, respectivamente. Enquanto que, nos ambientes de regiões altimontanas e de planalto esses valores mínimo e máximo foram de 3,5 e $105,7 \mathrm{~g} \mathrm{~kg}^{-1}$. Esses resultados mostram o agrupamento dos Organossolos em função do ambiente de formação para definir recomendações e práticas de manejo, bem como a fragilidade desses solos aos processos de subsidência e mineralização da matéria orgânica do solo (MOS).

Por outro lado, nos Organossolos dos ambientes de altitude a fração humina apresentou teor médio de $\mathrm{C}$ de 42,4 $\mathrm{g} \mathrm{kg}^{-1}$ e DP de 29,7, valores inferiores aos encontrados nos ambientes de várzeas ou planícies litorâneas, porém com elevado CV (71\%), embora esse seja inferior ao CV do conjunto total dos perfis (77\%) (Tabela 2). Para os Organossolos dos ambientes de altitude houve predomínio da fração ácido húmico sobre as demais frações húmicas, exceto pelo perfil MG-2 e horizonte Hd2 do perfil DF (Tabela 3), com os maiores valores de C-FAH de $153,7 \mathrm{~g} \mathrm{~kg}^{-1}$, assim como as maiores médias $\left(75,1 \mathrm{~g} \mathrm{~kg}^{-1}\right)$. Neste ambiente, de temperaturas médias anuais mais baixas, parece haver favorecimento da formação da fração ácido húmico.

Os resultados podem ser avaliados pela relação FAH/FAF, que indica a qualidade do material humificado e informa sobre a dinâmica da MOS. Para os ambientes de altitude os valores da relação FAH/FAF variaram de 1,8 a $14,4 \mathrm{~g} \mathrm{~kg}^{-1}$, indicando predomínio da FAH sobre a FAF em todas as amostras. Destacando-se que quanto mais

Tabela 3 - Valores $\left(\mathrm{g} \mathrm{C} \mathrm{kg}^{-1}\right)$ médios, máximos, mínimos, teor de matéria orgânica e de $\mathrm{C}$ nas substâncias húmicas, em todos os perfis e em função do ambiente de formação

\begin{tabular}{|c|c|c|c|c|c|c|c|}
\hline & MO_mufla & Ctotal & FAF & FAH & HUM & FAH/FAF & EA/HUM \\
\hline \multicolumn{8}{|c|}{ Ambiente de várzeas e planícies litorâneas } \\
\hline $\operatorname{Max}$ & 963,2 & 528,5 & 51,0 & 193,8 & 267,2 & 11,5 & 1,6 \\
\hline Min & 530,9 & 120,7 & 9,2 & 22,0 & 79,2 & 2,0 & 0,4 \\
\hline Média & 787,0 & 404,7 & 24,9 & 142,0 & 196,0 & 6,4 & 0,9 \\
\hline DP & 129,9 & 114,8 & 10,8 & 45,4 & 60,1 & 3,0 & 0,3 \\
\hline $\mathrm{CV}(\%)$ & 16,0 & 28,0 & 43,0 & 32,0 & 31,0 & 47,0 & 33,0 \\
\hline \multicolumn{8}{|c|}{ Ambiente altimontano e de planalto } \\
\hline $\operatorname{Max}$ & 485,4 & 270,0 & 23,7 & 153,7 & 105,7 & 14,4 & 9,9 \\
\hline Min & 93,4 & 44,8 & 7,3 & 22,1 & 3,5 & 1,8 & 0,7 \\
\hline Média & 260,0 & 150,3 & 15,3 & 75,1 & 42,0 & 5,5 & 3,5 \\
\hline DP & 111,1 & 59,6 & 4,4 & 42,4 & 29,7 & 3,9 & 2,5 \\
\hline $\mathrm{CV}(\%)$ & 43,0 & 40,0 & 29,0 & 56,0 & 71,0 & 71,0 & 72,0 \\
\hline
\end{tabular}


elevada essa relação maior será o grau de polimerização da MOS (CASTILLO; WRIGHT, 2008; KONONOVA, 1982; ORLOV, 1985). Os ácidos húmicos refletem tanto a condição de gênese como o manejo dos solos. Assim, Organossolos com altos teores de $\mathrm{MO}$ em regiões de temperaturas amenas $\left(<18{ }^{\circ} \mathrm{C}\right)$, tendem a apresentar maior fertilidade natural (BAYER et al., 2006; EBELING et al., 2008; LAL, 2004). Nesses solos há favorecimento da formação da fração ácido húmico e os valores de relação FAH/FAF são superiores a 1 (um) (KONONOVA, 1982; STEVENSON, 1994).

$\mathrm{O} \mathrm{C}$ da fração ácido fúlvico apresentou os menores valores, com média de $20,1 \mathrm{~g} \mathrm{~kg}^{-1}$. A FAF mostrou DP 9,5 $\mathrm{g} \mathrm{kg}^{-1}$ e uma menor variabilidade, com $\mathrm{CV}$ de $47 \%$ nos dois ambientes estudados. O menor valor encontrado da $\operatorname{FAF}\left(7,3 \mathrm{~g} \mathrm{~kg}^{-1}\right)$ foi superior àquele correspondente de HUM $\left(3,5 \mathrm{~g} \mathrm{~kg}^{-1}\right)$ enquanto que seu maior valor de C-FAF foi de $51 \mathrm{~g} \mathrm{~kg}^{-1}$ (Tabela 3). A prevalência de ácidos fúlvicos nos solos de reação ácida pode resultar, em longo prazo, em ambientes menos favoráveis à atividade microbiana, com concomitante redução da fertilidade do solo (BENITES et al., 2005; MILORI et al., 2002; SILVA; ANDERSON; GUILHERME., 2000) e a menor intensidade de transformação da matéria orgânica do solo.

Para os Organossolos formados em ambientes de várzeas e de planícies litorâneas o $\mathrm{C}$ da FAF apresentou o menor valor médio $\left(24,9 \mathrm{~g} \mathrm{~kg}^{-1}\right)$, com baixa variabilidade e CV de $43 \%$. Esses valores são muito próximos dos observados para Organossolos de regiões altimontanas e de planalto, que tiveram para o $\mathrm{C}$ da FAF os menores valores médios $\left(15,3 \mathrm{~g} \mathrm{~kg}^{-1}\right)$, menor variabilidade e CV de $(29 \%)$. A predominância de ácidos fúlvicos é explicada pela presença de condições que limitam a humificação como a baixa soma de bases (valor $\mathrm{S}$ ) teores de $\mathrm{Al}^{3+}$, baixa temperatura em ambientes altimontanos e hidromorfismo nas demais situações (CASTILLO; WRIGHT, 2008; CUNHA et al., 2007), como consequência tem-se uma menor quantidade de ácidos húmicos.

Os valores da relação entre o $\mathrm{C}$ da FAH/FAF variaram de 1,8 a 14,4 $\mathrm{g} \mathrm{kg}^{-1}$, no conjunto dos solos estudados, indicando predomínio do $\mathrm{C}$ da FAH em todas as amostras, destacando-se que quanto mais alta essa relação maior o grau de polimerização da MOS (BENITES et al., 2005; KONONOVA, 1982; VALLADARES et al., 2007).

A relação do $\mathrm{C}$ do EA/HUM, também teve grande variação entre as amostras, com valores entre 0,4 e 9,9 (Tabela 2). Porém, no conjunto dos solos estudados, $79 \%$ das amostras apresentaram valores < 2. Segundo Benites et al. (2005), essa relação pode fornecer informações relevantes sobre processos pedogenéticos, identificando zonas de movimentação ou acúmulo de carbono.
A seguir são destacados os ambientes de formação dos Organossolos estudados e discutidos os resultados obtidos no fracionamento químico, as relações entre as frações húmicas e outros parâmetros químicos dos Organossolos de várzeas e planícies litorâneas.

Nesses ambientes costeiros desenvolveram-se solos tiomórficos. Os solos tiomórficos são representados pelos perfis AL, BA, SC e RS, enquanto os não tiomórficos são representados pelo perfil RJ-03.

Nos Organossolos tiomórficos os valores de $\mathrm{C}$ da relação FAH/FAF foram de médio a altos $(2,4$ a 11,5), indicando, portanto, condições ambientais que favorecem a formação do $\mathrm{C}$ da FAH em profundidade (Tabela 2). Os menores valores de $\mathrm{C}$ da relação $\mathrm{FAH} / \mathrm{FAF}$ nos horizontes superficiais podem ser devidos à maior intensidade do processo de oxidação (maior aeração), favorecendo a formação de ácidos fúlvicos (VALLADARES et al., 2008). No perfil AL essa relação diminuiu abruptamente no horizonte Hoj, em relação ao valor em superfície, o que pode estar relacionado às condições permanentes de saturação por água.

Os valores de $\mathrm{C}$ da relação EA/HUM foram inferiores a 1 (um) na maioria dos horizontes com exceção do Hdoj3 do BA com valor de 1,2, o que pode indicar variação na natureza do material orgânico de origem.

O Organossolo não tiomórfico (perfil RJ-3) apresentou teor de C da FAF acima da média (24,0 a 51,0 $\left.\mathrm{g} \mathrm{kg}^{-1}\right)$ e, similar aos solos tiomórficos, apresentou domínio de $\mathrm{C}$ da fração HUM. A relação do C da FAH/FAF variou entre 2 e 4, inferior à observada em solos formados a partir de material mineral. Já a relação EA/HUM variou entre 1,1 e 1,6 nos três horizontes superficiais (Hdp, Hdo1 e Hdo2), e foi < $1(0,6)$ no Hdo, que se apresenta de natureza fíbrica (EBELING, 2006). O que é um indicativo da extração indevida de substâncias não húmicas durante a etapa de obtenção das amostras. O perfil RJ-3 apresentou baixa relação $\mathrm{C} / \mathrm{N}$ (14 a 18), capacidade de troca de cátions (CTC) variando de 43,8 a 59,4 $\mathrm{cmol}_{\mathrm{c}} \mathrm{kg}^{-1}$, $\mathrm{pH}$ em água fortemente ácidos de 4,8 a 5,3, soma de bases (valor $\mathrm{S}$ ) de 23,2 a $27,8 \mathrm{cmol}_{\mathrm{c}} \mathrm{kg}^{-1}$ e saturação por bases (valor V) de 44 a $58 \%$ (caracterização química mais detalhada em EBELING et al., 2008). Esses valores são relativamente altos, inclusive os horizontes Hdo1 e Hdo2 têm caráter eutrófico, sendo esse solo o que apresenta a melhor fertilidade natural, dentre os Organossolos estudados. Entretanto, o perfil RJ-3, classificado como Organossolo Háplico Hêmico térrico, é pouco profundo $(90 \mathrm{~cm}$ de espessura) e possui alto potencial de subsidência, como inferido pelos maiores valores do C da relação EA/HUM (Tabela 2), entre os perfis em ambiente de várzea.

$\mathrm{O}$ perfil RJ-4 de região altimontana e de planalto elevado (Tabela 2) apresentou material orgânico sáprico; entretanto, o horizonte Hdp1 mostrou maior teor de fibras 
esfregadas (maiores detalhes em Ebeling, 2006). Quanto às frações húmicas, todos os horizontes (Hdp1, Hdp2, Hdp3 e Hd) tiveram predomínio de $\mathrm{C}$ na FAH. As relações do $\mathrm{C}$ da FAH/FAF foram baixas $(<2)$, indicando maior formação de $\mathrm{C}$ da FAF. O perfil apresentou relação do C do EA/HUM que variou de 2,2 a 9,9, com o valor máximo no horizonte Hdp3, coincidindo com o aumento de material mineral, observado em outro estudo no mesmo perfil (VALLADARES et al., 2007). Dentre todos os perfis de Organossolos estudados, o RJ-4 foi o único com valores de C da relação EA/HUM superiores aos de $\mathrm{C}$ da relação FAH/FAF.

Quanto aos parâmetros indicadores de fertilidade natural (EBELING et al., 2008), a baixa soma de bases (valor $\mathrm{S}<3,0 \mathrm{cmol}_{\mathrm{c}} \mathrm{kg}^{-1}$, a exceção do Hdp1 com valor $\mathrm{S}$ de 7,6 $\mathrm{cmol}_{\mathrm{c}} \mathrm{kg}^{-1}$ ) e o caráter distrófico foram os principais limitantes. Os valores de $\mathrm{pH}$ em água são moderadamente ácidos $(5,5$ a 5,9$)$, para solos de natureza orgânica, e o $\mathrm{Al}$ não ocorreu em teor tóxico. $\mathrm{O}$ referido perfil apresentou baixa CTC variando de 22,9 a 27,9 $\mathrm{cmol}_{\mathrm{c}} \mathrm{kg}^{-1}$ considerado baixo para Organossolos. A relação $\mathrm{C} / \mathrm{N}$ variou de 18 a 32 . Esse solo possui baixo potencial de subsidência, como indicado pelo teor de $\mathrm{C}$ inferior a $100 \mathrm{~g} \mathrm{~kg}^{-1}$, altos valores de densidade do solo (Ds) entre 0,80 e 0,97 $\mathrm{Mg} \mathrm{m}^{-3}$, e resíduo mínimo (RM) entre 0,43 e $0,57 \mathrm{~cm} \mathrm{~cm}^{-1}$.

O perfil MG-2 apresentou teores de C de 114,8 a 206,4 $\mathrm{g} \mathrm{kg}^{-1}$ (Tabela 2). O material orgânico foi predominantemente hêmico (caracterização física mais detalhada em EBELING, 2006). De modo contrário aos outros Organossolos desenvolvidas em regiões de altitude mais elevada, as frações húmicas dos horizontes hísticos desse Organossolo apresentaram predomínio de $\mathrm{C}$ da HUM. O C da relação FAH/FAF variou entre 3,2 e 5,8 nos horizontes do perfil, enquanto que o $\mathrm{C}$ da relação EA/ HUM foi baixa, variando de 0,8 a 1,0 .

Os principais fatores limitantes à produção agrícola são a baixa soma de bases $\left(2,1\right.$ a $\left.5,8 \mathrm{cmol}_{\mathrm{c}} \mathrm{kg}^{-1}\right)$ e o caráter distrófico (caracterização química mais detalhada em EBELING et al., 2008). Os valores de $\mathrm{pH}$ em água situam-se entre 4,5 e 5,1, com presença de Al em níveis tóxicos. De modo semelhante ao perfil RJ-4 os horizontes desse perfil apresentaram baixos valores de CTC (15,3 a 51,3 cmol $\mathrm{kg}^{-1}$ ) para Organossolos. A relação $\mathrm{C} / \mathrm{N}$ variou de média a baixa (15 a 22). Em virtude de suas propriedades (baixos valores de Ds $\left(0,18\right.$ a $\left.0,41 \mathrm{Mg} \mathrm{m}^{-3}\right) \mathrm{e}$ de $\operatorname{RM}\left(0,05\right.$ a $\left.0,22 \mathrm{~cm} \mathrm{~cm}^{-1}\right)$, o perfil MG-2 foi considerado como de risco moderado a alto à subsidência.

Os perfis DF, MS, SP e PR apresentaram teores de $\mathrm{C}$ total entre 121,1 e 270,0 $\mathrm{g} \mathrm{kg}^{-1}$, na maioria dos horizontes e são predominantemente sápricos (caracterização física mais detalhada em (EBELING, 2006). A Ds variou de média a alta, entre $\left(0,39\right.$ e $\left.0,80 \mathrm{Mg} \mathrm{m}^{-3}\right)$ nesses perfis.
O potencial de subsidência foi considerado como de moderado a baixo. Nesses perfis, houve predomínio do $\mathrm{C}$ na FAH sobre as demais frações húmicas. $\mathrm{O}$ que resultou em elevados valores de $\mathrm{C}$ da relação EA/HUM, na maioria das amostras acima de 2, alcançando o máximo em 6,1 no horizonte Hdp2 do perfil SP. Os horizontes com menores valores dessa relação, numericamente, têm entre 0,8 e 2,0 de C na relação EA/HUM. O teor mais elevado de material mineral $(>51 \%)$ nesses solos pode favorecer o predomínio do $\mathrm{C}$ na FAH, haja vista a afinidade entre os constituintes orgânicos e a fração mineral (VALLADARES et al., 2007). $\mathrm{O}$ C da relação FAH/FAF foi, em geral, superior a 4.

A maioria dos solos apresentou valor $\mathrm{S}$ inferior a 8,0 $\mathrm{cmol}_{\mathrm{c}} \mathrm{kg}^{-1}$ e valores fortemente ácidos de $\mathrm{pH}(4,0$ a 5,2), caracterizando solos de baixa fertilidade entre os Organossolos. A exceção foi o perfil DF, com valor $\mathrm{S}$ dos horizontes Hdp e $\mathrm{Hd} 2$ de 18,9 e 21,0 cmol $\mathrm{kg}^{-1}$, respectivamente, possuindo o primeiro horizonte caráter eutrófico. A relação $\mathrm{C} / \mathrm{N}$ foi bastante variável, com valores de 15 a 40.

\section{Relações entre frações húmicas e ambientes de formação}

O somatório das frações húmicas representou em média $89 \%$ do $\mathrm{C}$ total, sendo as duas variáveis altamente correlacionadas (Figura 1).

Quando a correlação foi realizada para agrupar os Organossolos conforme seus ambientes de formação (Figura 2), os solos de ambiente de planalto e regiões altimontanas apresentaram maior coeficiente de determinação $\left(\mathrm{R}^{2}=0,90, \mathrm{p}>0,001\right)$ que os solos nas várzeas e planícies litorâneas $\left(R^{2}=0,88, p>0,001\right)$.

De um total de 32 amostras dos perfis coletados, 3 (três) apresentaram maiores valores de $\mathrm{C}$ na FAF do que $\mathrm{C}$ na HUM, representados por horizontes com teores de $\mathrm{C}$ orgânico relativamente baixos, limítrofes para serem classificados como hísticos e com baixos teores de fibras esfregadas (caracterização física mais detalhada em

Figura 1 - Relação entre a soma das frações húmicas e o teor de carbono total

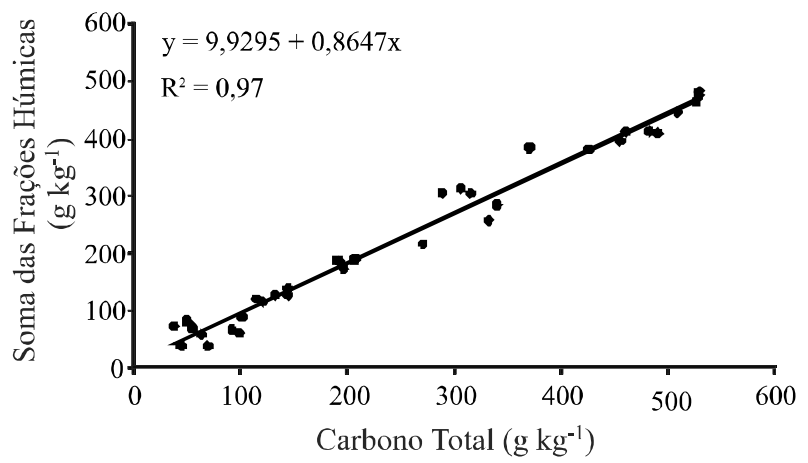


Figura 2 - Relação entre a soma das frações húmicas e o teor de carbono total em função do ambiente de formação (planícies litorâneas versus planaltos elevados)

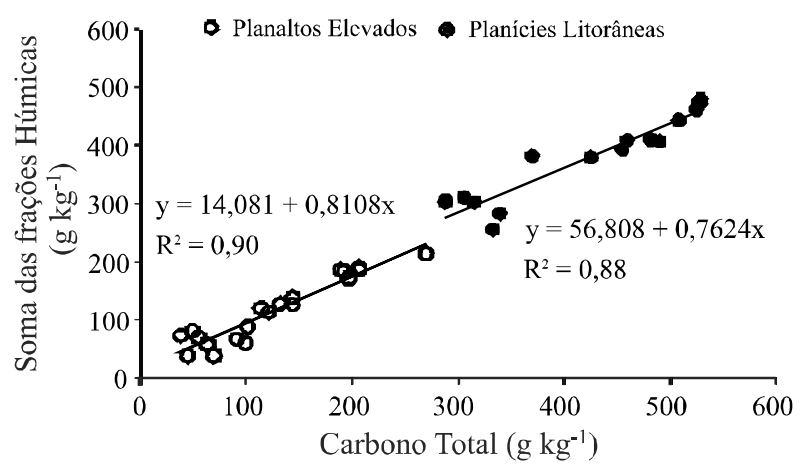

(Ebeling, 2006), correspondentes aos horizontes Hdp2, Hdp3 e Hd do perfil RJ-4, Organossolo hidromórfico da região de Nova Friburgo (RJ). Em 15 (quinze) amostras os teores de $\mathrm{C}$ na FAH foram superiores aos de C na HUM, em geral horizontes com baixas quantidades de fibras esfregadas.

Quando agrupados os Organossolos em função o ambiente de formação, percebe-se (Tabela 3) uma clara distinção entre os solos através do $\mathrm{C}$ da relação EA/ HUM. Ao avaliar os perfis em cada ambiente, os solos de várzeas e planícies litorâneas apresentam relação EA/ HUM < 2 (máxima de 1,6), enquanto os altimontanos e de planalto apresentam, na sua maioria, valores de relação EA/HUM > 2 (máxima de 9,9).

Em vista dos resultados obtidos, aponta-se a necessidade de validação de relações encontradas com outros parâmetros e métodos analíticos, como, por exemplo, a determinação da composição elementar dos ácidos húmicos purificados e liofilizados, a relação $\mathrm{C} /$ $\mathrm{N}$ e a relação $\mathrm{E}_{4} / \mathrm{E}_{6}$ (parâmetro utilizado na análise por espectroscopia de UV-VIS em substâncias húmicas - razão entre a absorvância em 465 nm 4665 nm de soluções aquosas diluídas). Como já discutido, o fracionamento químico empregado apresentou alguns inconvenientes para os Organossolos, superestimando os valores de humina ao contabilizar formas de $\mathrm{C}$ não solúveis em meio alcalino, incluindo fibras e outros materiais orgânicos.

No entanto, é possível sugerir o uso da relação EA/HUM como atributo diagnóstico para distinção dos Organossolos do SiBCS (EMPRESA BRASILEIRA DE PESQUISA AGROPECUÁRIA, 2006), no nível de família e série ( $5^{\circ}$ e $6^{\circ}$ níveis categóricos). Essa relação permitiu o agrupamento de Organossolos em função do ambiente na formação das SHs. O que é importante para o uso desses solos, já que os Organossolos de várzeas e planícies litorâneas são mais susceptíveis à subsidência se drenados corrigidos e cultivados, principalmente com a aplicação de calcário. A adição de elevadas doses de $\mathrm{CaCO}_{3}$ e a consequente elevação do $\mathrm{pH}$ do solo desestabilizam os complexos húmicos com alumínio, e por conseguinte as moléculas orgânicas, tornando-as mais susceptíveis ao ataque microbiano. Os Organossolos formados em ambientes de várzea são, em geral, mais ácidos o que dificulta o ataque microbiano e favorece a preservação da matéria orgânica, diminuindo a subsidência quando drenados.

\section{CONCLUSÕES}

1.O teor de $\mathrm{C}$ nas frações húmicas da MOS indicou predomínio da fração ácido húmico nos solos de regiões altimontanas e ambientes de planalto. Já no ambiente de várzeas e de planícies litorâneas houve predomínio da fração humina;

2. A diferenciação entre os Organossolos em função do ambiente de formação foi relevante para avaliar as frações da matéria orgânica e seu comportamento, permitindo sugerir práticas de manejo para a manutenção da matéria orgânica e a redução da subsidência destes solos;

3. A relação EA/HUM se mostrou promissora para agrupar classes de Organossolos conforme o ambiente de formação, sendo sugerida como atributo diagnóstico nos níveis inferiores do SiBCS.

\section{REFERÊNCIAS}

AMBAK, K.; MELLING, L. Management practices for sustainable cultivation of crop plants on tropical peatland. Proceedings of the International Symposium on Tropical Peatlands. Bogor, Indonesia: Hokkaido University \& Indonesian Institute of Sciences, 2000. p. 119-134.

ANDRIESSE, J. Uso de solos orgânicos em condições tropicais e subtropicais aliado às possibilidades brasileiras. In: SIMPÓSIO NACIONAL DE SOLOS ORGÂNICOS, 1984. Curitiba, Anais... Curitiba: MA:Provárzeas Nacional, Embrater, SEAG - Paraná e Acarpa / Emater - Paraná, 1984. v. 1. p. 11-34.

BAYER, C. et al. C and $\mathrm{N}$ stocks and the role of molecular recalcitrance and organomineral interaction in stabilizing soil organic matter in a subtropical Acrisol managed under no-tillage. Geoderma, v. 133, n. 3/4, p. 258-268, 2006.

BENITES, V. M. et al. Properties of black soil humic acids from high altitude rocky complexes in Brazil. Geoderma, v. 127, n. 1/2, p. 104-113, 2005.

BENITES, V. M.; MADARI, B.; MACHADO, P.L. O. A. Extração e fracionamento quantitativo de substâncias húmicas do solo: um procedimento simplificado de baixo custo. Rio de Janeiro: Embrapa Solos, 2003. 7 p. (Comunicado Técnico, 16). 
CASTILLO, M. S.; WRIGHT, A. L. Soil phosphorus pools for Histosols under sugarcane and pasture in the Everglades, USA. Geoderma, v. 145, n. 1/2, p. 130-135, 2008.

CONCEIÇÃO, M. Natureza do húmus e caracterização de solos com elevado teor de matéria orgânica da região de Itaguaí - Santa Cruz, RJ. 1989. 169 f. Dissertação (Mestrado em Agronomia - Ciência do Solo) Universidade Federal Rural Rio de Janeiro, Instituto de Agronomia - Departamento de Solos, Itaguaí, 1989.

CUNHA, T. J. F. et al. Fracionamento químico da matéria orgânica e características de ácidos húmicos se solos com horizonte a antrópico da Amazônia (Terra Preta). Acta Amazônica. v. 37, n. 1, p. 91-98, 2007.

DABIN, B. Méthode de extraction et de fractionnement des matières humiques du sol. Application a quelques études pédologiques et agronomiques dans les sols tropicaux. Cah. ORSTOM. Serie Pedology, v. 14, n. 4, p. 287-297, 1976.

DAI, X. Y.; PING, C. L.; MICHAELSON, G. J. Characterizing soil organic matter in Arctic tundra soils by different analytical approaches. Organic Geochemistry, v. 33, n. 4, p. 407-419, 2002.

DAVIDSON, E. A.; JANSSENS, I. A. Temperature sensitivity of soil carbon decomposition and feedbacks to climate change. Nature, v. 440, p. 165-173, 2006.

DICK, D. P. et al. Characteristics of soil organic matter of different Brazilian Ferralsols under native vegetation as a function of soil depth. Geoderma, v. 124, n. 3/4, p. 319-333, 2005.

DRADJAD, M. et al. Subsidence of peat soils the tidal swamplands of Barambai, south Kalimantan. Jurnal IImu Tanah dan Lingkungan, v. 4, n. 1, p. 32-40, 2003.

EBELING, A. G. Caracterização analítica da acidez em Organossolos. 2006. 97 f. Dissertação (Mestrado em Agronomia) - Universidade Federal Rural Rio de Janeiro, Instituto de Agronomia - Departamento de Solos, Seropédica RJ, 2006.

EBELING, A. G. et al. Relação entre acidez e outros atributos químicos em solos com teores elevados de matéria orgânica. Bragantia, v. 67, n. 2, p. 261-266, 2008.

EBELING, A. G. et al. Atributos químicos, carbono orgânico e substâncias húmicas em Organossolos Háplicos de várias regiões do Brasil. Revista Brasileira de Ciência do Solo, v. 35, n. 2, p. 325-336, 2011a.

EBELING, A. G. et al. Substâncias húmicas e relação com atributos edáficos. Bragantia, v. 70, n. 1, p. 157-165, 2011 b.

EMPRESABRASILEIRADEPESQUISAAGROPECUÁRIA. Centro Nacional de Pesquisa de Solos. Sistema brasileiro de classificação de solos. 2. ed. Rio de Janeiro, 2006. 306 p.

EMPRESA BRASILEIRA DE PESQUISA AGROPECUÁRIA. Centro Nacional de Pesquisa de Solos. Manual de métodos de análises de solos. 2. ed. Rio de Janeiro, 1997. 212 p.

FONTANA, A et al. Classificação de horizontes diagnósticos em níveis hierárquicos inferiores com base nas frações húmicas. Revista Brasileira de Ciência do Solo, v. 35, n. 2, p. 313-324, 2011.
HAYES, M. H. B.; CLAPP, C. E. Humic substances: considerations of compositions, aspects of structure, and environmental influences. Soil Science, v. 166, n. 11, p. 723-727. 2001.

KONONOVA, M. M. Materia orgánica del suelo: su naturaleza, propiedades y métodos de investigación. Barcelona: Oikos-tau, 1982. 364 p.

LAL, R. Soil carbon sequestration impacts on global change and food security. Science, v. 304, n. 5677, p. 1623-1627, 2004.

LIMA, L. A. Drenagem de solos agrícolas. 2008. 20 p. Disponível em: <http://www.lalima.com.br/lalima/arquivos/ drenagem.pdf $>$. Acesso em: 10 set. 2008.

MILORI, D. M. B. P. et al. Humification degree of soil humic acid determined by fluorescence spectroscopy. Soil Science, v. 167, n. 11, p. 739-749, 2002.

NOVOTNY, E. H. et al. Effect of residual vanadyl on the spectroscopic analysis of humic acids. Organic Geochemistry, v. 37 , n. 11 , p. $1562-1572,2006$.

ORLOV, R. Humic acids of soils. Washington: The National Science Foundation, 1985. 378 p.

SANTOS, R. D. et al. Manual de descrição e coleta de solo no campo. 5. ed. Viçosa: Sociedade Brasileira de Ciência do Solo, 2005. 92 p.

SILVA, C. A.; ANDERSON, S. J.; GUILHERME, L. R. G. Uso da cromatografia de exclusão por tamanho na caracterização de substâncias húmicas de Latossolo Vermelho-Escuro sob efeito de calagem. Revista Brasileira de Ciência do Solo, v. 24, n. 3, p. 495-503, 2000.

STEVENSON, F. J. Humus chemistry: genesis, composition, reactions. 2. ed. USA: John Wiley \& Sons, 1994. 496 p.

TAN, K. H. Humic Matter in Soil and the Environment Principles and Controversies. New York: Marcel Dekker, Inc., 2003. 398 p.

TATE III, R. L. Microbial oxidation of organic matter of Histosols. Advances in Microbial Ecology. v. 4, p. 169-201, 1980.

VALLADARES, G. S. et al. Caracterização de solos brasileiros com elevado teor de matéria orgânica. Magistra, v. 20, n. 1, p. 95-104, 2008.

VALLADARES, G. S. et al. Humic substances fractions and attributes of histosols and the related high-organic-matter soils from Brazil. Communications in Soil Science and Plant Analysis, v. 38, p. 763-777, 2007.

VAlladARES, G. S. et al. Proposta para classificação de Organossolos em níveis inferiores com base nas frações Húmicas. Campinas, Embrapa Monitoramento por Satélite, 2003. 35 p. (Boletim de Pesquisa e Desenvolvimento, 2).

WEST, T. O.; POST, W. M. Soil Organic Carbon Sequestration Rates by Tillage and Crop Rotation: A Global Data Analysis. Soil Science Society of American journal, v. 66, p. 19301946, 2002.

YEOMANS, J. C.;BREMNER, J. M. A rapid and precise method for routine determination of organic carbon in soil. Communications in Soil Science and Plant Analysis, v. 19, n. 13, p. 1467-1476, 1988. 